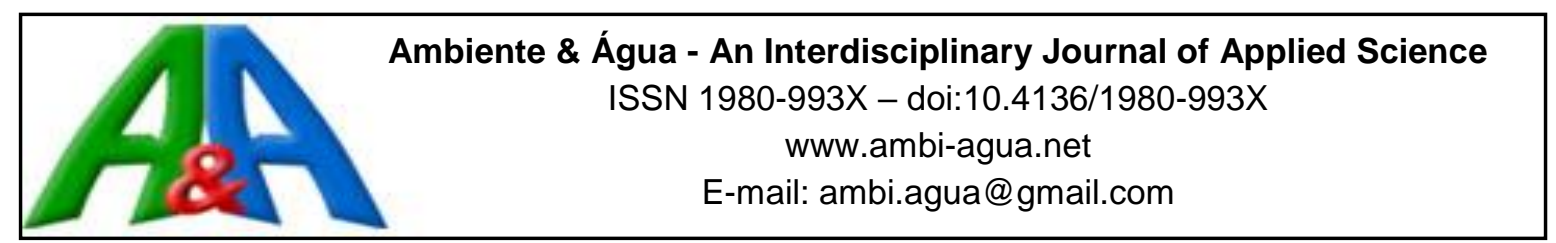

\title{
Classificação de estratos florestais utilizando redes neurais artificiais e dados de sensoriamento remoto
}

\author{
doi:10.4136/ambi-agua.1871
}

Received: 22 Feb. 2016; Accepted: 22 May 2016

\author{
Wanderson Gonçalves e Gonçalves ${ }^{*}$; Hebe Morganne Campos Ribeiro ${ }^{1}$; \\ José Alberto Silva de Sá ${ }^{1}$; Gundisalvo Piratoba Morales ${ }^{1}$; \\ Hélio Raymundo Ferreira Filho ${ }^{1}$; Arthur da Costa Almeida ${ }^{2}$ \\ ${ }^{1}$ Universidade do Estado do Pará (UEPA), Belém, PA, Brasil \\ Programa de Pós Graduação em Ciências Ambientais \\ ${ }^{2}$ Universidade Federal do Pará, UFPA, Castanhal, PA, Brasil \\ *Autor correspondente: e-mail: wanderson_goncalves@ rocketmail.com, \\ hebemcr@gmail.com, prof.albertosa@gmail.com, gundymorales@gmail.com, \\ hlio.ferreira@gmail.com, arthuralm@gmail.com
}

\section{RESUMO}

O presente estudo objetivou a classificação de tipologias florestais por meio de redes neurais artificiais utilizando dados provenientes de um inventário florestal, fornecido pelo Instituto de Desenvolvimento Florestal e da Biodiversidade do Estado do Pará (IDEFLORBIO), e das bandas 3, 4 e 5 do TM do satélite Landsat 5. As informações provenientes das imagens de satélite foram extraídas por meio do aplicativo QGIS 2.8.1 Wien e utilizadas no banco de dados para o treinamento das redes neurais pertencentes às ferramentas do software MATLAB $^{\circledR}$ R2011b. Foram treinadas redes neurais como classificadores de dois tipos florestais: Floresta Ombrófila Densa de Terras baixas Dossel emergente (Dbe) e Floresta Ombrófila Densa Terras baixas Dossel emergente mais Aberta com palmeiras (Dbe + Abp) no conjunto de glebas estaduais Mamuru-Arapiuns, Pará, e avaliadas usando os indicadores matriz de confusão, cálculo de acurácia global, coeficiente Kappa e o gráfico de características do receptor operacional (ROC). O melhor resultado de classificação foi obtido por meio da rede neural probabilística de função de base radial (RBF) "newpnn”, com uma acurácia global de $88 \%$, e coeficiente Kappa de $76 \%$, sendo avaliado como um classificador muito bom, evidenciando a aplicação dessa metodologia na análise de áreas com potencial para prestar serviços ecossistêmicos e, principalmente, na prestação de serviços ambientais em áreas antrópicas que adotam sistema de produção agropecuária com baixa emissão de carbono na Amazônia.

Palavras-chave: classificador neural probabilístico, inteligência artificial, inventário florestal.

\section{Classification of forest types using artificial neural networks and remote sensing data}

\section{ABSTRACT}

This study classified forest types using neural network data from a forest inventory 
provided by the "Florestal e da Biodiversidade do Estado do Pará" (IDEFLOR-BIO), and Bands 3, 4 and 5 of TM from the Landsat satellite. The information from the satellite images was extracted using QGIS software 2.8.1 Wien and was used as a database for training neural networks belonging to the software tools package MATLAB ${ }^{\circledR}$ R2011b. The neural networks were trained to classify two forest types: Rain Forest of Lowland Emerging Canopy (Dbe) and Rain Forest of Lowland Emerging Canopy plus Open with palm trees (Dbe + Abp) in the Mamuru Arapiuns glebes of Pará State, and were evaluated in terms of the indicators confusion matrix, overall accuracy, the Kappa coefficient, and the receiver operating characteristics chart (ROC). The best result of classification was obtained by the probabilistic neural network of radial basis function (RBF) newpnn, with an overall accuracy of $88 \%$, and a Kappa coefficient of $76 \%$, showing it to be a very good classifier, and demonstrating the potential of this methodology to provide ecosystem services, particularly in anthropogenic areas in the Amazon that adopt agricultural systems with low carbon emissions.

Keywords: artificial intelligence, forest inventory, neural probabilistic classifier.

\section{INTRODUÇÃO}

A região amazônica atualmente está cada vez mais sob os holofotes do mundo, uma vez que corresponde a um amplo reservatório de carbono, contendo grande parte do total de biomassa das plantas terrestres. Associados a isso, os altos níveis de desflorestamento e queimadas, justificam a necessidade de maiores estudos desta região, uma vez que este conhecimento contribui para a manutenção da fauna, da flora, da qualidade e quantidade da água, das condições climáticas e de outros serviços ecossistêmicos que comprometem diretamente a qualidade de vida da população (Ribeiro et al., 2009).

O sensoriamento remoto é a ciência que possibilita a aquisição de informações (espectral, espacial, temporal) de objetos materiais sem a necessidade de contato físico com o objeto de investigação. Neste contexto, o uso das técnicas de sensoriamento remoto torna-se indispensável, sobretudo devido à extensão territorial da região, dificuldades de acesso e custos elevados para realização de trabalhos de campo. Logo, o sensoriamento remoto, assume importante papel para a estimativa e monitoramento de vários fenômenos, proporcionando tomadas de decisão e análises de grandes territórios (Ferraz et al., 2014).

Estes registros de informações são exclusivamente adequados para mudanças de mapeamento na superfície da Terra, incluindo o desmatamento, expansão agrícola, perda de zonas húmidas, a expansão urbana e outras conversões de terra (Gutman et al., 2013).

Nos últimos anos, as Redes Neurais Artificiais tiveram um crescente interesse e têm sido usadas com bastante êxito no gerenciamento de informações do ambiente e em reconhecimento de padrões de imagens proveniente de Sensoriamento Remoto (Chagas et al., 2009; Espinhosa e Galo, 2004; Moreira et al., 2013).

Redes neurais artificiais são sistemas de processamento de informação formados pela interconexão de unidades simples de processamento, denominadas neurônios artificiais, os quais funcionam de acordo com a sua arquitetura, conexões entre as unidades de processamento, e os pesos gerados, mostrando-se relevante por tratar de funções não lineares e multidimensionais o que a torna capaz de lidar com complexas relações estatísticas (Almeida et al., 2009).

Ribeiro e Centeno (2001) utilizaram Redes Neurais Artificiais para classificar imagens do Landsat - TM, bandas 5, 4, e 3 e ao compararem os resultados com o método de classificação supervisionado mais comum, Máxima Verossimilhança (Maxver), concluíram que quando se dispõe de um número pequeno de amostras, o uso das RNA é mais eficiente, confirmando a viabilidade do uso das RNA para a classificação de imagens orbitais. 
Espinhosa e Galo (2004), aplicaram as Redes Neurais Artificiais na classificação da água e macrófitas aquáticas emersas para verificar a ambiguidade entre as classes em uma área teste do reservatório de Barra Bonita, SP, utilizando como dados de entrada imagens orbitais ETM+/Landsat e obtiveram resultados satisfatórios, permitindo uma boa separação espectral de duas ocorrências distintas de macrófitas emersas e variações na água. A utilização de RNAs ainda mostrou-se eficaz em estimativas de estoque de biomassa aérea através de dados de sensoriamento remoto (Ferraz et al., 2014) e em classificações da cobertura do solo, utilizadas para separar o solo descoberto da cobertura do solo, com índice de exatidão global médio na classificação de $82,10 \%$ e na classificação de fertilidade aparente para diferenciação de terras para fins de irrigação, obtendo-se $78 \%$ dos resultados iguais aos desejados (Varella et al., 2002).

Diversas pesquisas utilizaram Redes Neurais Artificiais na Classificação de diferentes classes de informação associadas à dados de sensoriamento remoto. $\mathrm{O}$ presente estudo visa a classificação de duas tipologias florestais, provenientes de um inventário florestal fornecido pelo Instituto de Desenvolvimento Florestal do Pará (IDEFLOR), associados a imagens do Satélite LandSat 5TM, por meio de Redes Neurais, avaliando a eficiência das redes neurais artificiais como classificador de dois tipos florestais, Floresta Ombrófila Densa de Terras baixas Dossel emergente (Dbe) e Floresta Ombrófila Densa Terras baixas Dossel emergente + Aberta com palmeiras (Dbe + Abp), no conjunto de glebas estaduais Mamuru-Arapiuns, Pará.

\section{MATERIAL E MÉTODOS}

\subsection{Caracterizações da área de estudo}

Os dados da área de estudo foram disponibilizados pelo Instituto de Desenvolvimento Florestal e da Biodiversidade do Estado do Pará (IDEFLOR-BIO), por meio do documento "Inventário Florestal Diagnóstico do Conjunto de Glebas Estaduais Mamuru-Arapiuns, Pará". A região analisada está localizada entre os municípios de Santarém, Juruti e Aveiro, no Estado do Pará, abrangendo uma área aproximada de 600.000 hectares (Figura 1). A planície ocupa a porção Norte e Leste do Entorno (ED) e constitui basicamente as áreas de várzeas formadas pelo rio Amazonas e o delta dos igarapés e rios tributários nessa porção, como o rio Mamuru. Essa planície é submetida às inundações sazonais do rio Amazonas (Seat Terraplanagem, 2010). Os solos da região compõem-se com Latossolo Amarelo para as áreas de terra-firme e nas áreas alagáveis e próximas dos grandes cursos d’água da região como o rio Amazonas é classificado como Gleissolo Háplico (EMBRAPA, 2007).

O clima da região é do tipo Amw de Köppen, caracterizado como quente e úmido, com a estação chuvosa nos meses de dezembro a junho e estação seca, de julho a novembro. A temperatura média anual é de $27,7^{\circ} \mathrm{C}$ com média anual de precipitação pluviométrica em torno de $1.950 \mathrm{~mm}$ (Miranda, 1995).

\subsection{Material}

Foram utilizadas as bandas do TM (Thematic Mapper) 3, 4 e 5 do satélite Landsat 5, adquiridas do site USGS (earthexplorer.usgs.gov), pertencentes a órbita/ponto 228/62 e 228/63, ambas de 23/10/2009, com resolução espacial de 30 x 30 m, com correção geográfica. As imagens foram escolhidas seguindo o critério de compatibilidade entre a data da imagem e a data de execução do inventário, com o objetivo de minimizar as variações temporais nas tipologias florestais. Tanto o inventário florestal, quanto as imagens são do ano de 2009. Foram utilizadas duas cenas, devido haver pontos de amostragem distribuídos em ambas as imagens. 


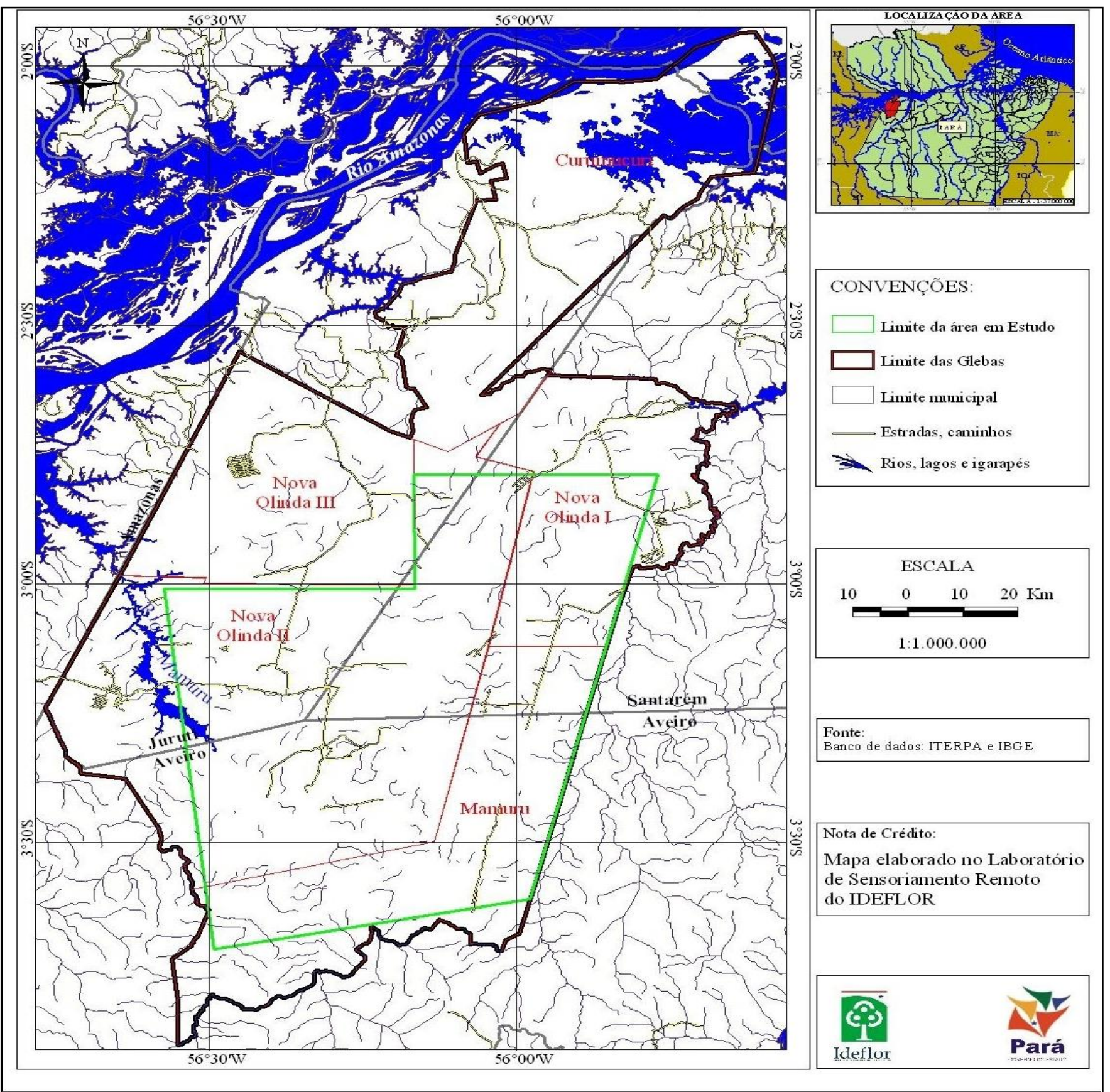

Figura 1. Mapa de Localização do Conjunto de Glebas Mamuru-Arapiuns.

\subsubsection{Inventário Florestal}

A amostragem realizada no inventário florestal do conjunto de Glebas Estaduais Mamuru-Arapiuns seguiu o definido pelo Serviço Florestal Brasileiro. As amostragens foram do tipo Amostragem Estratificada (Figura 2). A Amostragem Estratificada foi adotada para as tipologias florestais predominantes, Floresta Ombrófila Densa Terras baixas Dossel emergente (Dbe) e Floresta Ombrófila Densa Terras baixas Dossel emergente + Aberta com palmeiras (Dbe $+\mathrm{Abp}$ ), onde foram distribuídos aleatoriamente 30 conglomerados (15 unidades para cada estrato), sendo que cada unidade é constituída de 8 subunidades de $20 \times 200$ m cada. 


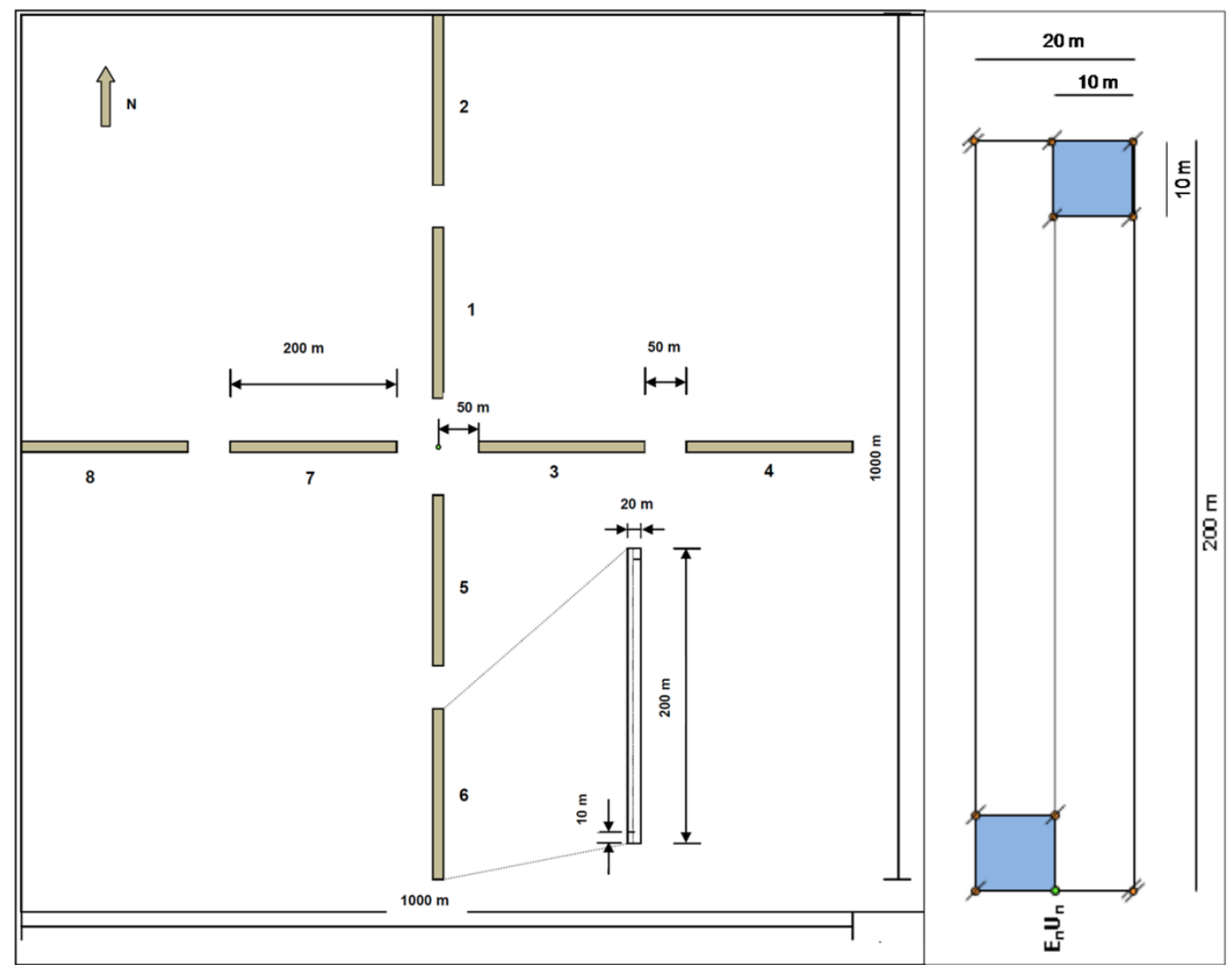

Figura 2. A) Esquema de Amostragem estratificada e B) Esquema da subunidade da amostragem.

Fonte: Adaptado de Seat Terraplanagem (2010).

O inventário ainda forneceu as coordenadas geográficas do ponto central de cada conglomerado para os estratos (Dbe e Dbe $+\mathrm{Abp}$ ).

\subsection{Metodologia no QGIS}

O software QGIS 2.8 Wien foi utilizado para a montagem do mosaico e junção das cenas do LandSat 5TM. Foram plotados os pontos centrais dos conglomerados e das subunidades nas imagens de satélite, no Sistema de coordenadas de referência (SRC) WGS 84, posteriormente foram extraídos os "Digital Numbers" (DN) puros de cada pixel constituintes das subunidades de cada estrato florestal, referentes à banda 3, 4 e 5 e o "Normalized Difference Vegetation Index ” (NDVI) constituindo a massa de dados.

O NDVI foi calculado de acordo com Rouse et al. (1973), utilizando a banda 4 (B4) e a banda 3 (B3), descrito na Equação 1:

$$
N D V I=\frac{(B 4-B 3)}{(B 4+B 3)}
$$

Para a obtenção dos "Digital Numbers" (DN), foi seguida a seguinte metodologia: Cada subunidade das amostras por conglomerado é dimensionada em $20 \times 200 \mathrm{~m}$, entretanto o tamanho do pixel das imagens orbitais tem a dimensão de $30 \times 30 \mathrm{~m}$, para compensar isto, optou-se por selecionar sete pixels, a partir do ponto central para cobrir toda a área de cada subunidade amostral, totalizando $210 \mathrm{~m}$ por subunidade. Desta maneira as planilhas de dados foram formadas pelas colunas contendo as coordenadas da região, os valores de DN das bandas 3, 4 e 5, e o NDVI. 
Posteriormente, os dados foram normalizados com o propósito de reduzir as discrepâncias entre os valores de entrada, utilizando-se a normalização "min-max", que transformou os valores originais das variáveis de entrada em valores normalizados no intervalo [0, 1] (Sá et al., 2012). Este procedimento foi feito, primeiramente, para evitar a saturação da rede neural, uma vez que altos valores podem intervir na solução do problema e, posteriormente, para precaver que algumas variáveis de alto valor e pouca importância influenciassem em variáveis de pequena variação, porém, de grande importância (Chagas et al., 2009).

Foram selecionados de maneira aleatória dois conjuntos de dados independentes, um para treinamento e outro para teste. O número de exemplos do conjunto de dados de treinamento foi 400, sendo 200 exemplos para cada classe (Dbe e Dbe+Abp), e o tamanho do conjunto de dados de teste foi 100, sendo 50 exemplos para cada classe (Dbe e Dbe+Abp). Portanto a massa total de dados constituiu-se em 500 exemplos.

\subsection{Rede Neural Probabilística}

Utilizou-se neste estudo a rede neural probabilística "probabilistic neural network" (PNN), proposta por Specht (1990), adequada para problemas de classificação. Ela é estruturada em três camadas: a camada de entrada, a camada de base radial e a camada competitiva (Xu et al., 2014). A arquitetura da rede neural probabilística é apresentada na figura 3, onde: $X, H$ e $Y$ representam, respectivamente, as variáveis de entrada, os neurônios da camada oculta e as variáveis de saída da rede PNN e $\mathrm{k}, \mathrm{m}$ e $\mathrm{n}$ representam, respectivamente, o número de entradas, neurônios da camada oculta e saídas.

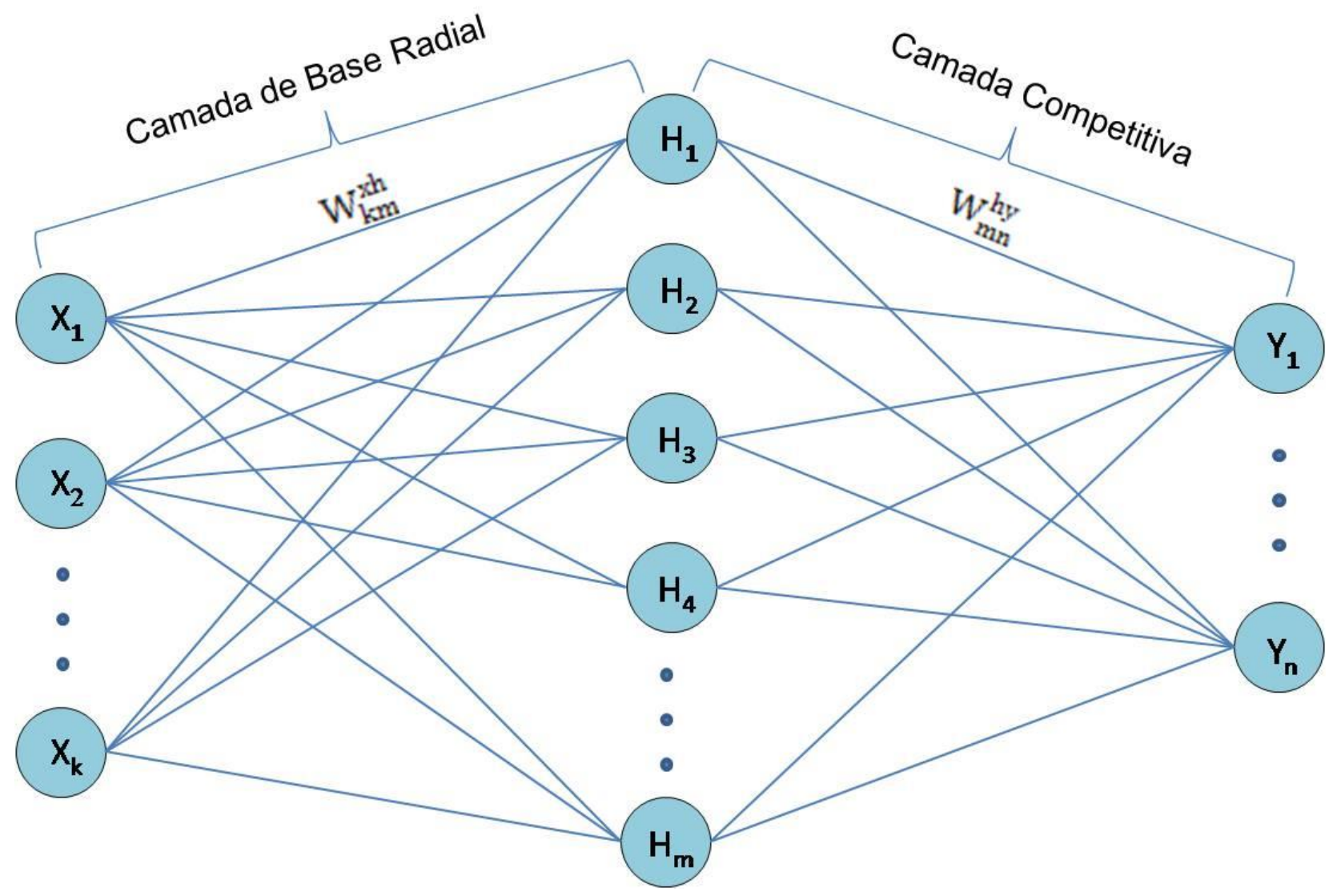

Figura 3. Arquitetura de uma rede neural RBF.

Fonte: Adaptado de Xu et al. (2014).

\section{IPABH}

Rev. Ambient. Água vol. 11 n. 3 Taubaté - July / Sep. 2016 
A rede neural probabilística foi treinada utilizando-se quatro parâmetros de entrada (B3, B4, B5 e NDVI), gerando como saída uma classificação pertencente ou não a determinado estrato florestal. O trabalho utilizou o algoritmo "newpnn" diponibilizado pelo MATLAB ${ }^{\circledR}$ R2011b. Para controlar a propagação de funções de base radial no PNN, uma função (spread) foi incluída. A rede PNN utilizada neste trabalho apresentou os melhores resultados de classificação para "spread" =0,2.

\subsection{Avaliação dos classificadores}

A avaliação da eficiência dos classificadores para cada tipologia florestal foi feita pela "matriz de confusão" ou "matriz de erro", acurácia global, nível de exatidão ou confiança da classificação (índice Kappa) e análise do gráfico ROC.

A matriz de confusão é uma técnica de análise de classificadores, onde cada coluna da matriz representa os resultados reais enquanto que cada linha corresponde aos resultados preditos pelo classificador (Figura 4).

\section{Classe Verdadeira}

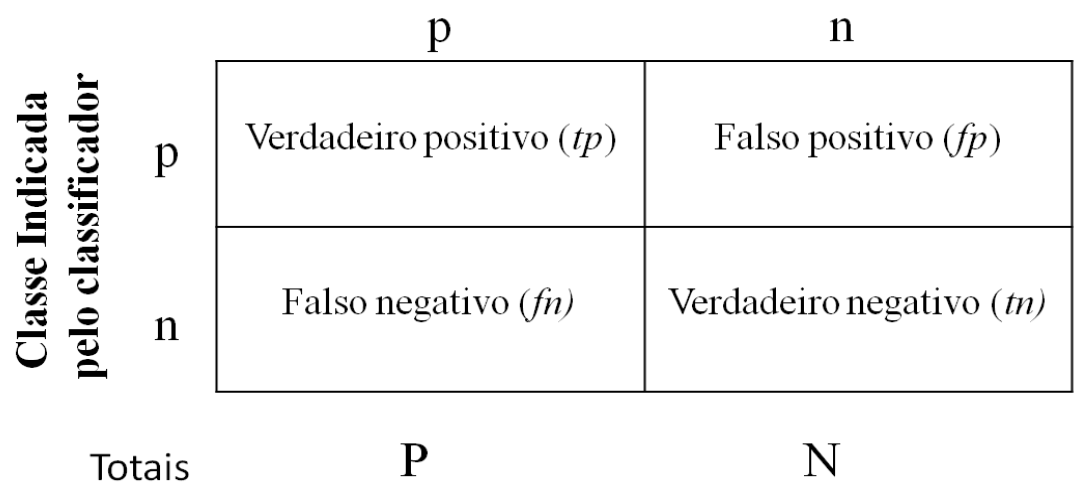

Figura 4. Modelo de matriz de confusão.

Fonte: Adaptado de Fawcett (2006).

A acurácia global foi calculada pela razão entre a soma dos verdadeiros positivos e verdadeiros negativos $(t p+t n)$ e a soma do total de positivos e negativos $(P+N)$, conforme descrito na Equação 2.

$$
A G=\frac{t p+t n}{P+N}
$$

O coeficiente Kappa foi calculado de acordo com a Equação 3 (Congalton e Green, 2009).

$$
\widehat{K}=\frac{N \sum_{i=1}^{r} x_{i i}-\sum_{i=1}^{r}\left(x_{i}+x_{+i}\right)}{N^{2}-\sum_{i=1}^{r}\left(x_{i}+x_{+i}\right)}
$$

em que:

$\widehat{\mathrm{K}}$ representa o estimador do coeficiente Kappa;

$r$ é o número de linhas da matriz quadrada;

$x_{i i}$ é o número de observações na linha i e da coluna i (diagonal principal);

$x_{i}$ e $x_{+i}$ representam o somatório na linha e na coluna, respectivamente; e 
$N$ representa o número total de observações.

O uso do coeficiente "Kappa" (K) é satisfatório para avaliar a precisão de uma classificação, devido levar em consideração, principalmente todos os elementos da matriz de confusão, diferente da acurácia global que utiliza somente a diagonal principal (Congalton e Green, 2009).

O coeficiente "Kappa” neste estudo é comparado aos índices apresentados na Tabela 1.

Tabela 1. Qualidade de classificação a partir dos valores do coeficiente Kappa.

\begin{tabular}{cl}
\hline Valor de Kappa & Qualidade \\
\hline$<0,00$ & Péssima \\
$0,00-0,20$ & Ruim \\
$0,20-0,40$ & Razoável \\
$0,40-0,60$ & Boa \\
$0,60-0,80$ & Muito boa \\
$0,80-1,00$ & Excelente \\
\hline
\end{tabular}

Fonte: Adaptado de Landis e Koch (1977).

O gráfico de características do receptor operacional (Gráfico ROC) é baseado na taxa de verdadeiros positivos tpr e na taxa de falsos positivos $f p r$ observados na matriz de confusão. Este gráfico é formado pela fpr no eixo das abscissas e tpr no eixo das ordenadas (Prati et al., 2008). A taxa de verdadeiros positivos (tpr) é obtida a partir do quociente entre o valor dos verdadeiros positivos $(t p)$ e o total de positivos $(P)$ e a taxa de falsos positivos é obtida mediante o quociente entre o valor dos falsos positivos $(f p)$ e o total de negativos $(N)$, como demonstrado pela Equação 4:

$$
t p r=\frac{t p}{P} \quad f p r=\frac{f p}{N}
$$

No gráfico ROC, a localização dos pares ordenados formados pelos valores da tpr (no eixo das ordenadas) e $f p r$ (no eixo das abscissas) é importante para avaliar o desempenho da classificação (Figura 5). O ponto [0,0] no canto inferior esquerdo indica que o classificador apresenta uma taxa de falsos positivo nula, entretanto, também apresenta uma taxa de verdadeiros positivos nula. O inverso acontece com o ponto superior direito $[1,1]$. O melhor cenário possível de um classificador, considerado como ideal, é uma classificação onde os pontos situam-se no canto superior esquerdo [0,1], onde $f p r$ é igual a 0 (valor mínimo) e tpr é igual a 1 (valor máximo) (Fawcett, 2006; Prati et al., 2008).

Pelo gráfico ROC, um classificador apresenta vantagem em relação a outro, quando ele possui uma taxa de verdadeiros positivos maior que o classificador comparado ou quando ele possui uma taxa de falsos positivos menor que o classificador comparado. Classificadores conservadores possuem taxas de falsos positivos baixas, porém apresentam também baixas taxas de verdadeiros positivos. Já os classificadores liberais têm altas taxas de verdadeiros positivos, porém eles também possuem altas taxas de falsos positivos (Fawcett, 2006; Sá et al., 2012). Na figura 5, comparando-se os classificadores A e B, A seria considerado um classificador conservador enquanto B seria considerado um classificador liberal. C representa um classificador aleatório, devido estar sobre a linha diagonal e D seria considerado um 
classificador ideal.

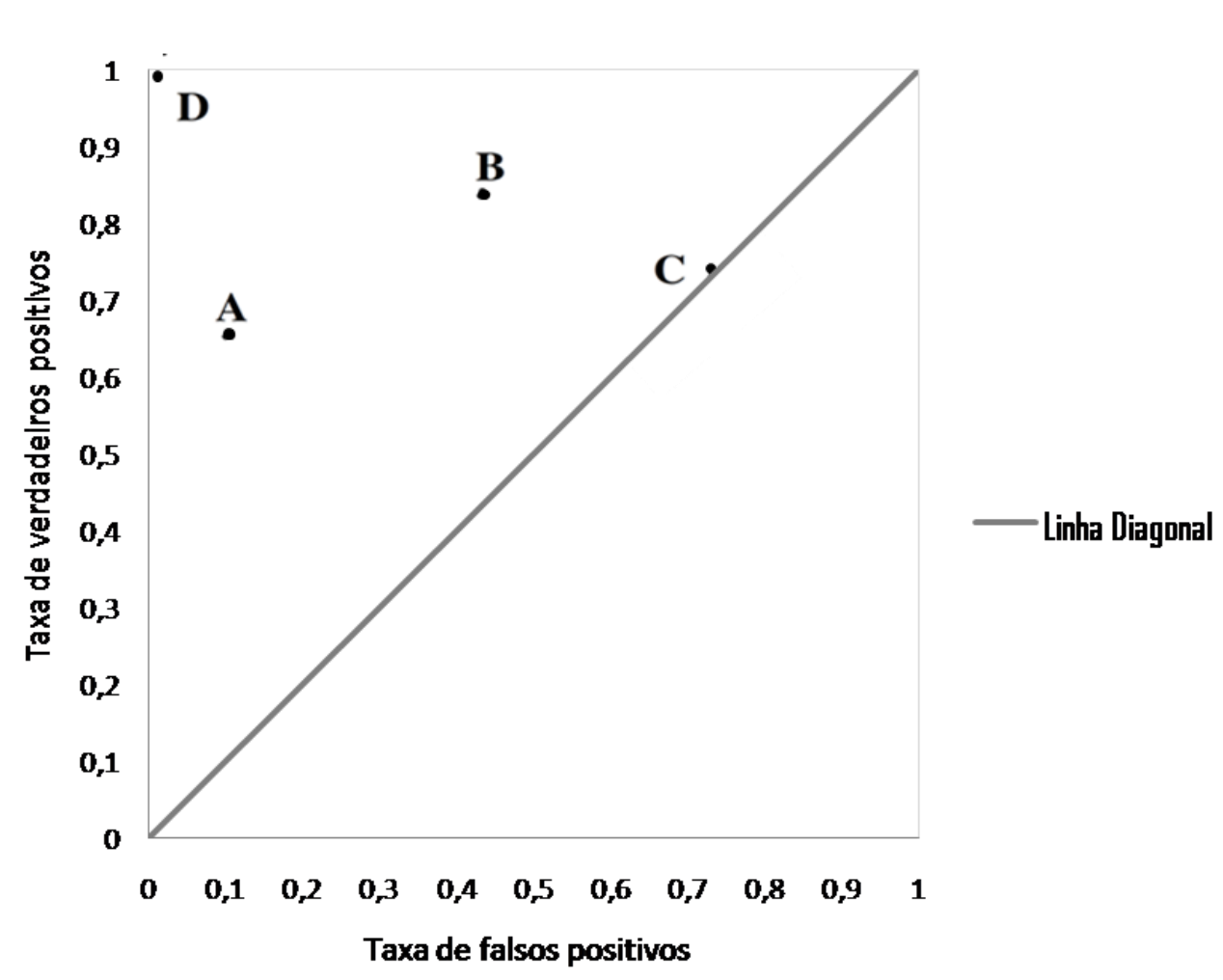

Figura 5. Gráfico ROC mostrando quatro classificadores discretos.

Fonte: Adaptado de Fawcett (2006).

\section{RESULTADOS E DISCUSSÃO}

Os resultados da Acurácia Global e Coeficiente "Kappa" obtidos com a variação do "Spread” na rede neural probabilística estão apresentados na Tabela 2.

Tabela 2. Resultados da Acurácia Global e Coeficiente "Kappa" com variação do "Spread".

\begin{tabular}{cccc}
\hline Rede & "Spread" & Acurácia Global & Coeficiente "Kappa" \\
\hline newpnn & 0,1 & $86 \%$ & $72 \%$ \\
newpnn & 0,2 & $88 \%$ & $76 \%$ \\
newpnn & 0,4 & $86 \%$ & $72 \%$ \\
newpnn & 0,6 & $85 \%$ & $70 \%$ \\
newpnn & 0,8 & $85 \%$ & $70 \%$ \\
newpnn & 1,0 & $84 \%$ & $68 \%$ \\
\hline
\end{tabular}

Nota-se que os melhores valores avaliativos para a classificação foram obtidos com o ajuste do"Spread" em 0,2. Os resultados da rede newpnn também são apresentados na matriz de confusão, exposta na Figura 6. 


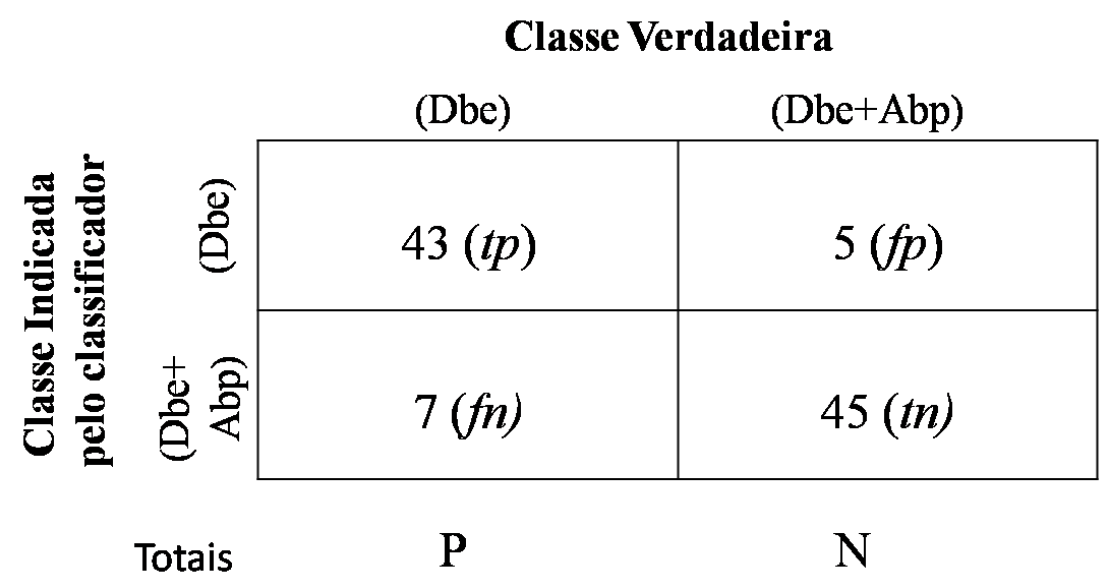

Figura 6. Matriz de confusão com os resultados do classificador.

O valor da acurácia global do classificador foi de $88 \%$, resultado ligeiramente superior ao trabalho de Varella et al. (2002), que utilizou uma rede neural de retropropagação do erro para classificar solo descoberto da cobertura do solo com vegetação na localidade Paraíso, no município de Viçosa, Minas Gerais, obtendo uma valor de acurácia global igual a 82,10\%.

Entretanto, como a acurácia global leva em consideração somente os resultados da diagonal principal, optou-se por calcular também o coeficiente "Kappa", cujo resultado foi de $76 \%$, sendo este avaliado, de acordo com Landis e Koch (1977), como um classificador muito bom. Todavia, mesmo valores de índice "Kappa”, elevados, próximos a 100\%, não garantem que os resultados obtidos na classificação sejam concordantes com a realidade de campo, pois o valor do coeficiente está relacionado com os dados da amostragem utilizada, mesmo quando os dados utilizados para a avaliação são diferentes dos da classificação, logo, mesmo sendo importante e significante a utilização do índice "Kappa”, na avaliação do classificador, outro método de avaliação deve ser empregado para a verificação final da qualidade da classificação (Moreira et al., 2013) para isto, utilizou-se também neste estudo a análise do gráfico ROC.

Foram classificados incorretamente como pertencentes ao estrato 2 (Dbe+Abp), enquanto que pertenciam ao estrato 1 (Dbe), 14\% dos pixels do estrato 1 (Dbe) e como pertencentes ao estrato 1 (Dbe), enquanto que pertenciam ao estrato 2 (Dbe+Abp), 10\% dos pixels do estrato 2 (Dbe+Abp). Sendo que 86\% do total de pixels do estrato 1 (Dbe) foram classificados corretamente para o estrato 1 (Dbe), e 90\% do total de pixels do estrato 2 (Dbe+Abp) foram classificados corretamente como estrato 2 (Dbe+Abp).

A rede "newpnn", devido a sua arquitetura de camadas de competição, devolve na saída da rede somente valores correspondentes a pertencer ou não a determinada classe, caracterizando-a como classificador discreto (Fawcett, 2006). Deste modo torna-se possível a construção do gráfico ROC. O gráfico ROC construído é apresentado na figura 7.

Percebe-se que o classificador apresenta uma característica conservadora para a rotulagem do estrato 1 (Dbe), quando comparado ao estrato 2 (Dbe+Abp), ou seja, ele apresenta $t p r$ e $f p r$ menores quando comparado as mesmas taxas para a classificação do estrato 2 (Dbe+Abp). Por conseguinte o classificador apresenta uma característica liberal para rotulagem do estrato 2 (Dbe+Abp), quando comparado ao estrato 1 (Dbe), isto é, apresenta tpr e $f p r$ maiores quando comparado às respectivas taxas de classificação do estrato 1 (Dbe).

Neste caso observamos que o classificador é mais conservativo para o estrato 1 e mais liberal para o estrato 2. Desta maneira, ao comparar a localização dos pontos deste classificador com a figura 5, também nota-se que a classificação é muito próxima ao ponto considerado como ideal, pois os pontos do classificador, além de estarem muito próximos, estão situados a noroeste do gráfico, o que de acordo com vários autores (Prati et al., 2008; Fawcett, 2006; Sá et al., 2012), configura-se como uma excelente classificação. 


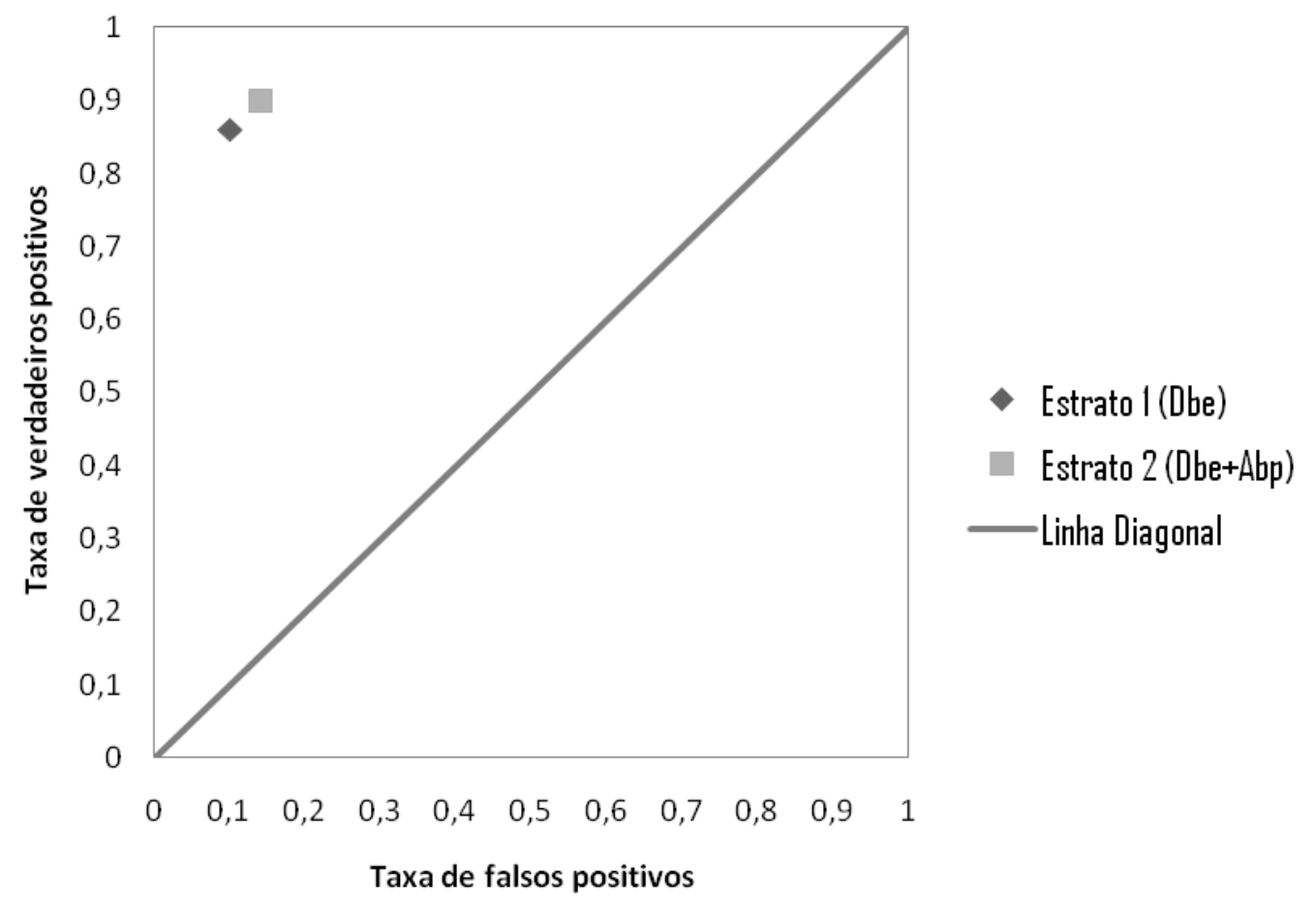

Figura 7. Gráfico ROC com dados do classificador

Observa-se no gráfico uma aproximação entre os pontos dos estratos, ou seja, o classificador apresenta um grau de eficiência de classificação similar para ambos os estratos.

\section{CONCLUSÃO}

A classificação de duas tipologias florestais que utiliza inventário florestal e as bandas 3, 4 e 5 do TM do Satélite Landsat 5, por meio da rede neural probabilística de base radial $(\mathrm{RBF})$, apresentou resultados satisfatórios, sendo identificada uma rede neural que apresentou uma acurácia global de $88 \%$, e coeficiente "Kappa" de 76\%, podendo ser considerado como um classificador "muito bom".

A análise do gráfico ROC demonstra visualmente a eficiência do classificador, uma vez que os pontos encontram-se a noroeste do gráfico e distante da linha diagonal (classificação aleatória).

É importante ressaltar que a tipologia florestal Floresta Ombrófila Densa Terras baixas Dossel emergente + Aberta com palmeiras é um estrato de transição entre a Dbe e Abp. Apesar desta característica o classificador forneceu resultados aceitáveis.

\section{AGRADECIMENTOS}

Os autores agradecem ao Instituto de Desenvolvimento Florestal e da Biodiversidade do Estado do Pará (IDEFLOR-BIO), no nome do Diretor Presidente Thiago Valente Novaes, por fornecer o inventário florestal utilizado neste estudo e à Coordenação de Aperfeiçoamento de Pessoal de Nível Superior (CAPES).

\section{REFERÊNCIAS}

ALMEIDA, A. C.; BARROS, P. L. C.; MONTEIRO, J. H. A.; ROCHA, B. R. P. Estimation of aboveground forest biomass in Amazonia with neural networks and remote sensing. IEEE Latin America Transactions, v. 7, n. 1, p. 27-32, 2009. 
CHAGAS, C. S.; VIEIRA, C. A.; FERNANDES FILHO, E. I.; CARVALHO JUNIOR, W. Utilização de redes neurais artificiais na classificação de níveis de degradação em pastagens. Revista Brasileira de Engenharia Agrícola e Ambiental, v. 13, n. 3, p. 319-327, 2009.

CONGAlton, R.; GREEN, K. Assessing the Accuracy of Remotely Sensed Data Principles and Practices. Boca Raton: CRC Press; Taylor \& Francis Group, 2009. 183 p.

EMPRESA BRASILEIRA DE PESQUISA AGROPECUÁRIA - EMBRAPA. Zoneamento ecológico-econômico da área de influência da rodovia BR-163 (Cuiabá-Santarém). Belém, 2007. p. 101.

ESPINHOSA, M. C.; GALO, M. de L. B. T. O uso de redes neurais artificiais na análise da ambigüidade entre classes de água e plantas aquáticas. Boletim de Ciências Geodésicas, v. 10, n. 2, 2004. http://dx.doi.org/10.5380/bcg.v10i2.1533

FAWCETT, T. An introduction to ROC analysis. Pattern recognition letters, v. 27, n. 8, p. 861-874, 2006. http://dx.doi.org/10.1016/j.patrec.2005.10.010

FERRAZ, A. S.; SOARES, V. P.; SOARES, C. P. B.; RIBEIRO, C.; BINOTI, D. H. B.; LEITE, H. G. Estimativa do estoque de biomassa em um fragmento florestal usando imagens orbitais. Floresta e Ambiente, v. 21, p. 286-296, 2014. http://dx.doi.org/10.1590/2179-8087.052213

GUTMAN, G.; HUANG, C.; CHANDER, G.; NOOJIPADY, P.; MASEK, J. G. Assessment of the NASA-USGS global land survey (GLS) datasets. Remote sensing of environment, v. 134, p. 249-265, 2013. http://dx.doi.org/10.1016/j.rse.2013.02.026

LANDIS, J. R.; KOCH, G. G. An application of hierarchical Kappa-type statistics in the assessment of majority agreement among multiple observers. Biometrics, p. 363-374, 1977. http://dx.doi.org/10.2307/2529786

MIRANDA, I. S. Fenologia do estrato arbóreo de uma comunidade de cerrado em Alter-doChão, PA. Revista Brasileira de Botânica, v. 18, n. 2, p. 235-240, 1995.

MOREIRA, G. F.; FERNANDES, R. B. A.; FERNANDES FILHO, E. I.; VIEIRA, C. A. O.; SANTOS, K. A. Classificação automatizada do uso e cobertura do solo a partir de imagens Landsat. Revista Brasileira de Geografia Física, v. 6, n. 1, p. 058-065, 2013.

PRATI, R. C.; BATISTA, G. E. A. P. A; MONARD, M. C. Curvas ROC para avaliação de classificadores. Revista IEEE América Latina, v. 6, n. 2, p. 215-222, 2008.

RIBEIRO, S. R. A.; CENTENO, J. S. Classificação do uso do solo utilizando redes neurais e o algoritmo MAXVER. In: SIMPÓSIO BRASILEIRO DE SENSORIAMENTO REMOTO, 20., 2001, Foz do Iguaçú. Anais... São José dos Campos: INPE, 2001. 1 CD-ROM.

RIBEIRO, S. C.; JACOVINE, L. A. G.; SOARES, C. P. B.; MARTINS, S. V.; SOUZA, A. L. D.; NARDELLI, A. M. B. Quantificação de biomassa e estimativa de estoque de carbono em uma floresta madura no município de Viçosa, Minas Gerais. Revista Árvore, v. 33, n. 5, p. 917-926, 2009. http://dx.doi.org/10.1590/S010067622009000500014 
ROUSE, J. W.; HAAS, R. H.; SCHELL, J. A.; DEERING, D. W. Monitoring vegetation systems in the great plains with ERTS. In: SYMPOSIUM OF SIGNIfiCANT RESULTS OBTAINED WITH ERTS-1, 3., 1973, Greenbelt, Maryland. Proceedings... Washington: NASA SP-351, 1973. . p. 309-317.

SÁ, J. A. S.; ROCHA, B. R. P.; ALMEIDA, A. C.; SOUZA J. R. Recurrent self-organizing map for severe weather patterns recognition. Recurrent Neural Networks and Solf Computing, p. 151-175, 2012.

SEAT TERRAPLANAGEM LTDA (Elab.). Inventário florestal diagnóstico do conjunto de glebas estaduais Mamuru-Arapiuns. Santarém, 2010.

SPECHT, D. F. Probabilistic neural networks and the polynomial Adaline as complementary techniques for classification. IEE Transactions Neural networks, vol. 1, p. 111-121, 1990. http://dx.doi.org/10.1109/72.80210

VARELlA, C. A.; PINTO, F. D. A. D. C.; QUEIROZ, D. M. D.; SENA JÚNIOR, D. G. Determinação da cobertura do solo por análise de imagens e redes neurais. Revista Brasileira de Engenharia Agrícola e Ambiental, v. 6, n. 2, p. 225-229, 2002. http://dx.doi.org/10.1590/S1415-43662002000200007

XU, S.; WU, C.; GONSAMO, A.; SHEN, Y. Delineation of Rain Areas with TRMM Microwave Observations Based on PNN. Remote Sensing, v. 6, n. 12, p. 12118-12137, 2014. http://dx.doi.org/10.3390/rs61212118 